\title{
Balloon Atrial Septostomy in an Infant with Tricuspid Atresia
}

\author{
Tetsuo Sato, Hiroshi Onoki and Ichmi Kano \\ Department of Pediatrics, \\ Tohoku University. School of Medicine, Sendai \\ Togo Horiuchi, Takeshi Ishitoya, TadaAki Abe, \\ Shigehiro Ishikawa, Shigeo Tanaka and Yoshiyuki \\ OKADA \\ Department of Surgery, \\ Tohoku University School of Medicine, Sendai
}

Sato, T., Onokt, H., Kano I., Horiuchi, T., Ishitoya, T., AвE, T., Ishikawa, S., Tanaka, S. and OKada, Y. Balloon Atrial Septostomy in an Infant with Tricuspid Atresia. Tohoku J. exp. Med., 1970, 101 (3), 281-288 — A fivemonth-old female with tricuspid atresia was successfully treated by Rashkind and Miller's balloon septostomy after banding of the pulmonary artery. tricuspid atresia; balloon septostomy

It has been well known that the prognosis of tricuspid atresia depends not only on the volume of the pulmonary blood flow but also on the size of the interatrial communication. This paper describes the usefulness of balloon atrial septostomy in tricuspid atresia with obstructed interatrial communication.

\section{Case Report}

A one-month-old female was admitted to our hospital because of cyanosis and dyspnea. She was born at term, weighing $3.4 \mathrm{~kg}$. A cardiac murmur was first noted 2 weeks before admission.

Physical examination revealed a poorly nourished, dyspneic and irritable baby with slight cyanosis around lips, weighing $4.3 \mathrm{~kg}$. The lungs were clear. A systolic murmur (Levine 4 grade) was heard at the left lower sternal border. The second sound was accentuaterl (cf. Fig. 1). Thrills were not palpable. The liver was felt 2 finger-breadths below the costal margin, but the spleen was not. Red blood cell count was 531$) \times 10^{4} / \mathrm{mm}^{3}$, hemoglobin was $17.0 \mathrm{~g} / 100 \mathrm{ml}$ and hematocrit was $50 \%$. The roentgenogram showed cardiac enlargement and marked increase in the pulmonary vascularity (cf. Fig. 2). The electrocardiogram revealed a regular sinus rhythm with left axis deviation ( -60 degrees), presenting evidence 


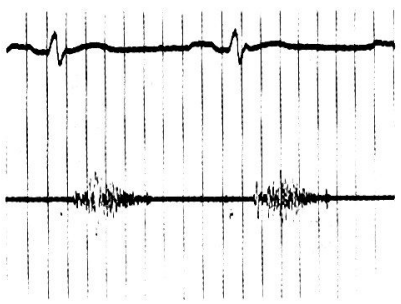

Aortic area

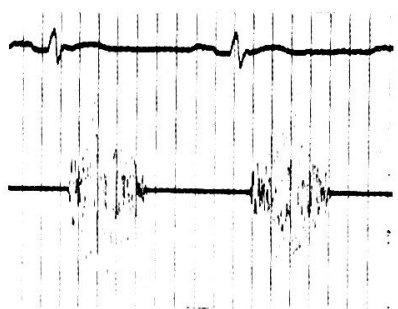

LLSB

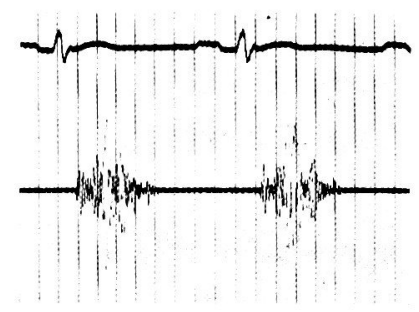

Pulmonic area

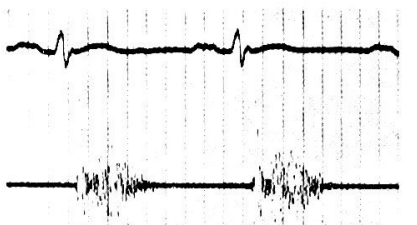

Apex

Fig. 1. 'The phonocardiogram of our patient. Note a systolic harsh murmur with the accentuated second sound.

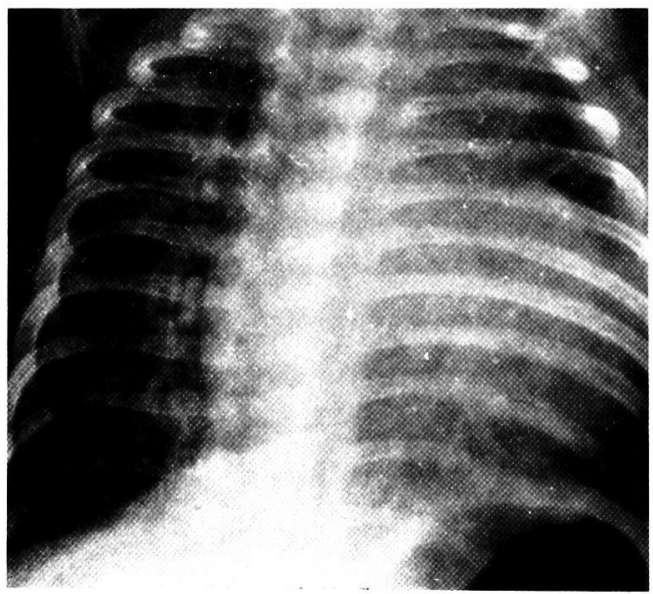

Fig. 2. The roentgenogram of our patient. Note cardiac enlargement and marked increase in the pulmonary vascularity.

of right atrial enlargement and left ventricular overloading (cf. Fig. 3). The vectorcardiogram (Frank's lead system) in the frontal plane rotated counterclockwise with figure-of-eight inscription (cf. Fig. 4).

These findings indicated tricuspid atresia with increased pulmonary blood flow. Despite of administrations of digitalis and diuretics, signs of congestive heart failure were not ameliorated. 


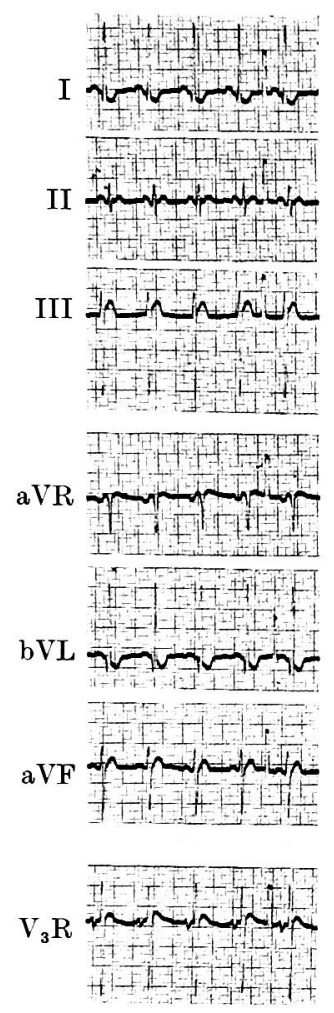

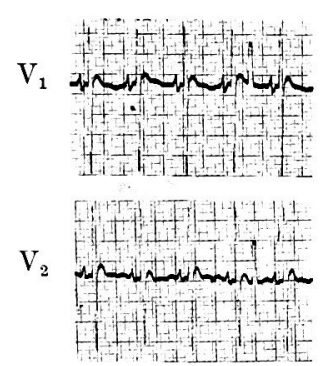
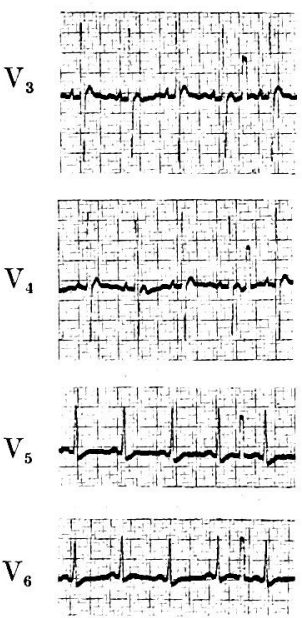

Fig. 3 .
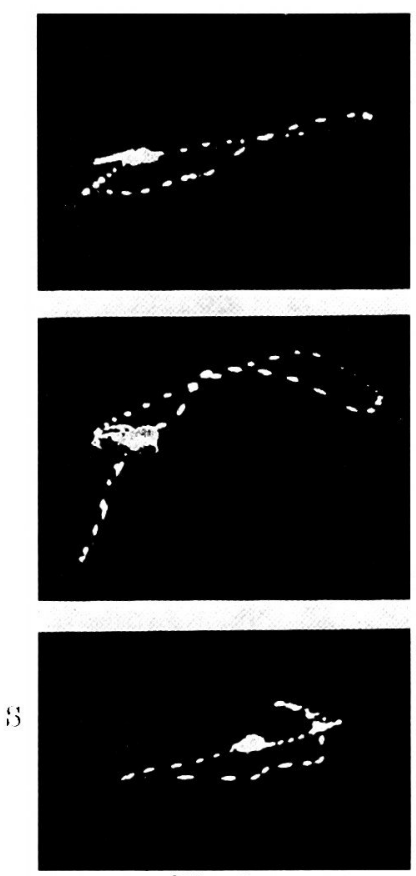

Fig. 4.

Fig. 3. The electrocardiogram of our patient. Note peaked $\mathbf{P}$ waves in the right precordial leads, the mean QRS axis of -60 degrees, the $r S$ pattern in $V_{1}$ and the $R_{5}$ pattern in $V_{6}$. These findings suggest right atrial enlargement and left ventricular overloading.

Fig. 4. The vectorcardiogram (Frank's lead system) of our patient. F: Frontal plane. $H$ : Horizontal plane. S: Left saggital plane. Note the QRS loop rotating counterclockwise with figure-of-eight inscription, suggesting left ventricular overloading.

On the 9th day of her admission, the cardiac catheterization was performed. The mean pressure in the right atrium was $4 \mathrm{~mm}$ and that in the left atrium was $1 \mathrm{~mm}$ of mercury. In the posteroanterior view of the cineangiocardiography with the injection of the contrast material into the right atrium, the contrast material passed from the right atrium to the left atrium through a slit-like interatrial communication. Nonopacification of the right ventricle resulted in the presence of a clear triangular zone with the base on the diaphragm. The typical sequence of opacification of heart chambers was not demonstrated because of obstructed interatrial communication (cf. Fig. 5). In the right anterior oblique view with the injection of the contrast material into the left atrium, both the great arteries were filled simultaneously without transposition. The pulmonary arterial trunk was markedly dilated (cf. Fig. 6). The left anterior oblique view with the same injection procedure demonstrated that there were a large ventricular septal defect, rudimentary right ventricle and dilated pulmonary arterial trunk with normal 


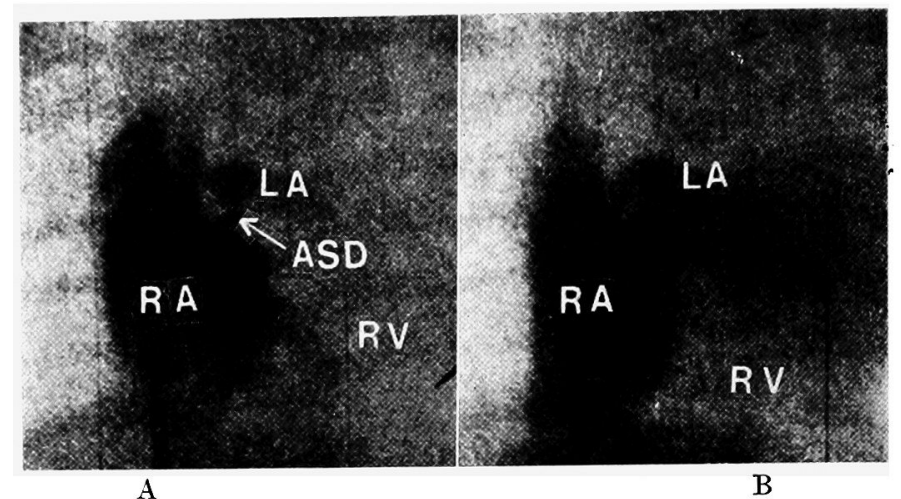

Fig. 5. The posteroanterior view of the cineangiocardiography with the injection of the contrast material into the right atrium. The contrast material passed from the right atrium to the left atrium through a slit-like interatrial communication (A). Nonopacification of the right ventricle resulted in the presence of a clear triangular zone with the base on the diaphragm (B).

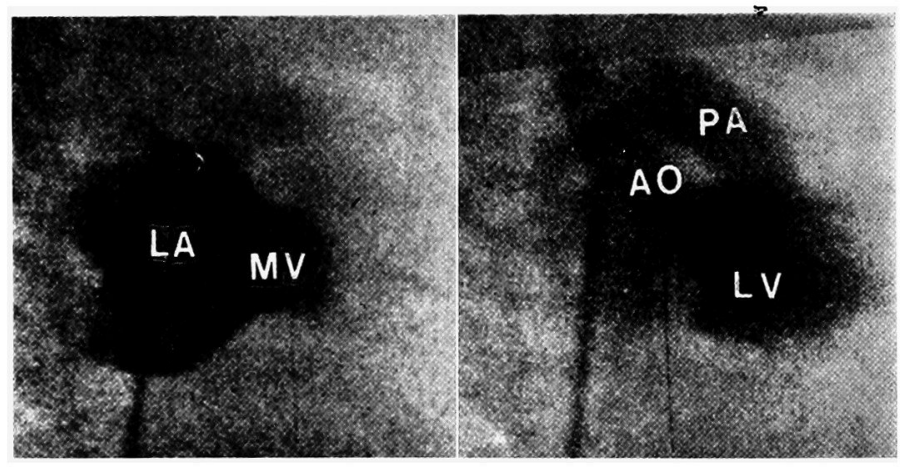

A

B

Fig. 6. The right anterior oblique view of the cineangiocardiography with the injection of the contrast material into the left atrium. The contrast material passed from the left atrium to the left ventricle through the mitral valve (A). The both great arteries originated simultaneously in the normal position. The pulmonary arterial trunk was larger than the aorta in diameter $(\mathrm{B})$.

situation (cf. Fig. 7). These cineangiocardiographic findings made a diagnosis of tricuspid atresia without transposition of the great arteries, associated with large ventricular septal defect and large pulmonary artery (Type I (C) of Keith et al. ${ }^{1}$ )

A banding of the pulmonary artery was performed to reduce the excessive pulmonary blood flow on the 3rd day of the catheterization. The surgery was performed via a posterolateral thoracotomy through the left 4th intercostal space. The aorta was $9 \mathrm{~mm}$ and the pulmonary arterial trunk was $11 \mathrm{~mm}$ in diameter, respectively. On the direct recordings, the pressure in the aorta was $50 / 38 \mathrm{~mm}$ and that in the pulmonary artery $50 / 20 \mathrm{~mm}$ of mercury (cf. Fig. 8). The pulmonary arterial trunk was gradually banded by the tape with a width of $4 \mathrm{~mm}$, until it was 


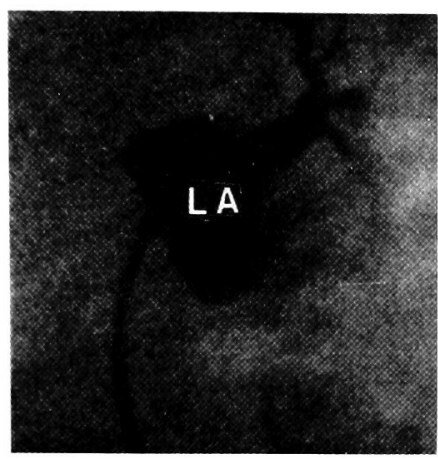

A

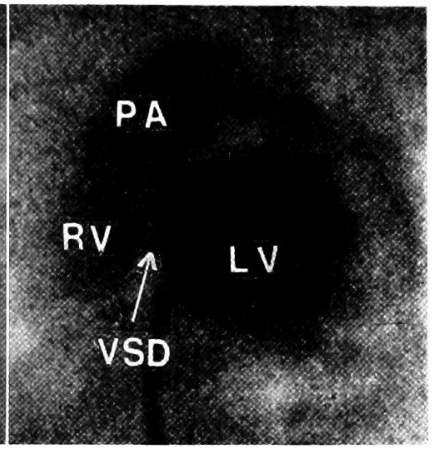

B

Fig. 7. The left anterior oblique view of cineangiocardiography with the injection of the the contrast material into the left atrium. After the injection (A), a large ventricular septal defect, rudimentary right ventricle and dilated pulmonary arterial trunk were demonstrated (B).

$6 \mathrm{~mm}$ in diameter. At the end of the procedure, the pressure in the aorta was $56 / 40 \mathrm{~mm}$ and that in the pulmonary artery $44 / 20 \mathrm{~mm}$ of mercury (cf. Fig. 8).

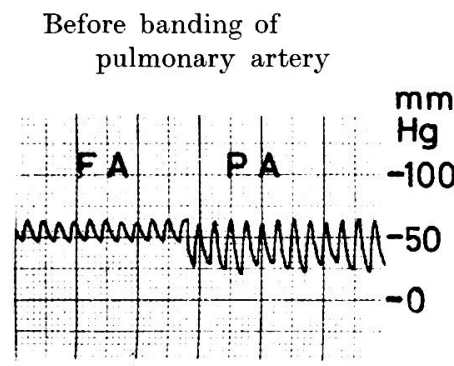

After banding of pulmonary artery

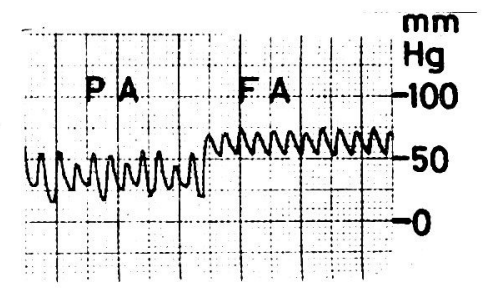

Fig. 8. The pressure recording in the both great arteries. The systolic pressure in the pulmonary artery was quite equal to that in the aorta (left). After the banding of the pulmonary artery, the systolic pressure in the pulmonary artery was $12 \mathrm{~mm}$ of mercury, and lower than that in the aorta (right).

After the operation, she was no longer dyspneic, but became more cyanotic. The pulmonary vascularity was diminished on the roentgenogram (cf. Fig. 9). She was discharged one month after the operation. She had been given the maintenance dosage of digitalis because of mild congestive heart failure. She gained the weight gradually.

She was readmitted at the age of 6 months because of severe edema which had suddenly appeared with anorexia, oliguria, vomiting and hematemesis. Administration of digitalis and diuretics was not effective. On admission, she was cyanotic and tachypneic, but not dyspneic. No rales were heard. A systolic harsh murmur was heard at the left lower sternal border but a gallop rhythm was not noted. The liver was palpable 2 finger-breadths below the costal margin. On the next day, the balloon atrial septostomy was performed in the same way as 


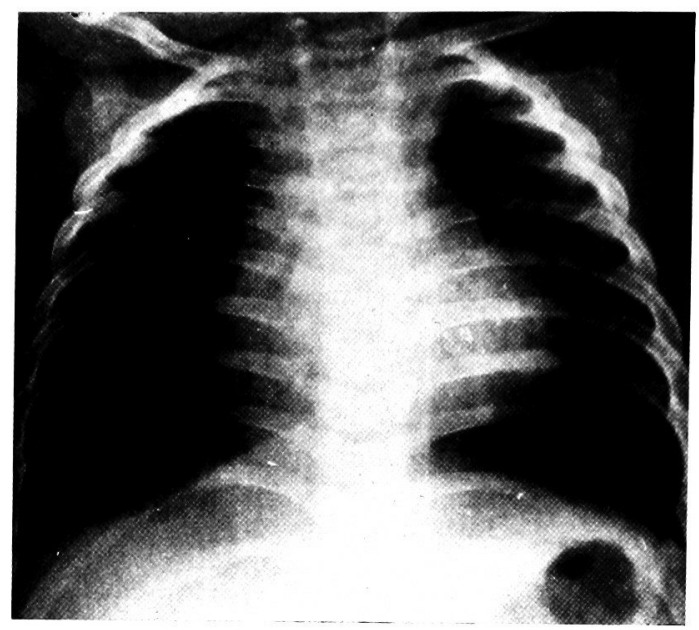

Fig. 9. The roentgenogram after the banding of the pulmonary artery. Note diminished pulmonary vascularity.

described previously. ${ }^{2}$ Before the procedure, the mean pressure in the right atrium was $13 \mathrm{~mm}$ and that in the left atrium was $1 \mathrm{~mm}$ of mercury. The right atrial pressure was remarkably elevated in comparison with that in the first catheterization performed at the age of 1 month. The interatrial communication was functionally obstructed more severely than before. After the procedure, the mean pressure in the right atrium was $9 \mathrm{~mm}$ and that in the left atrium was $6 \mathrm{~mm}$ of mercury. The pressure gradient between both atria was diminished (cf. Fig. 10).

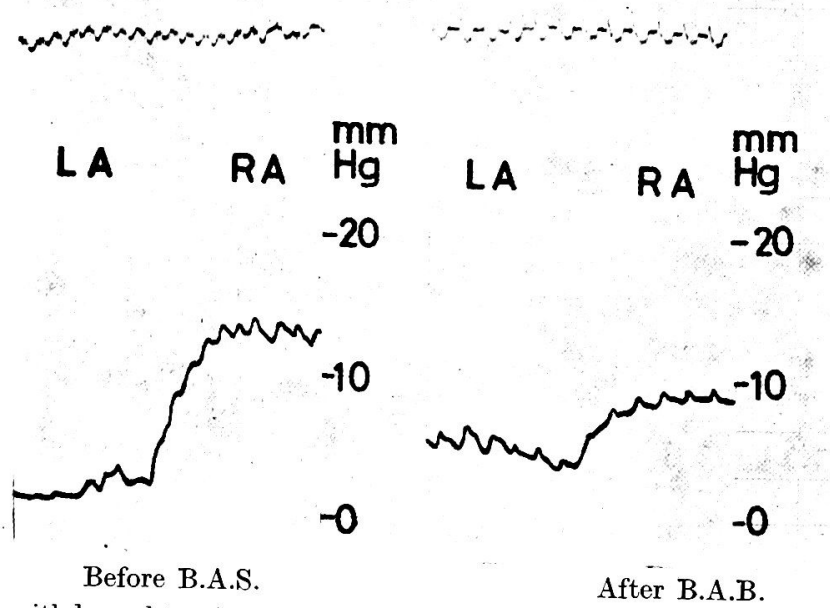

Fig. 10. The withdrawal tracings of pressure from the left atrium to the right atrium. Note a decrease of the pressure gradient between both atria after the balloon atrial septostomy. 
Soon after the atrial septostomy, the urinary amount was increased. She was no longer edematous and had lost $400 \mathrm{~g}$ in weight during 48 hours after the procedure. The clinical improvement by the balloon atrial septostomy was very dramatic. She was discharged on the 11th day of her admission and looked well.

\section{Comment}

Tricupsid atresia is one of the most serious congenital heart diseases. Its prognosis is usually very poor. Irrespective of various anatomical types of this malformation, the prognosis depends on the volume of the pulmonary blood flow and the size of the interatrial communication. Although the pulmonary blood flow is usually diminished, it is rarely so excessive that congestive heart failure is evident in early infancy. The banding of the pulmonary artery to reduce the excessive pulmonary flow is indicated in such a case. In four cases of Ochsner et $a l .{ }^{3}$ and one case of Rashkind et al., ${ }^{4}$ the banding of the pulmonary artery was performed with no mortality and no further evidence of congestive heart failure. In our case, an improvement in signs of congestive heart failure was achieved by the operation.

On the other hand, the interatrial communication is extremely variable in the size which influences inevitably the prognosis of the malformation. However, the surgical atrial septostomy (the Blalock-Hanlon's procedure) has seldom been applied to infants with obstructed interatrial communication, because of risk of this operation.

In 1966, Rashkind and Miller ${ }^{5}$ have predicted that the balloon atrial septostomy is useful not only for transposition of the great arteries with inadequate intracardiac mixing but also for tricuspid atresia with inadequate interatrial communication. However, there is only one report documented by Rashkind et al. ${ }^{4}$ in which 4 infants with tricuspid atresia were treated successfully by this procedure followed by anastomosis of ascending aorta to right pulmonary artery and one infant followed by pulmonary arterial banding.

The balloon atrial septostomy is safe and effective for infants with tricuspid atresia as well as for those with transposition of the great arteries. A dramatic improvement in the signs of congestive heart failure is seen immediately after the procedure. A remarkable decrease of left atrial-right atrial pressure gradient is a useful guide to the adequacy of the septostomy.

\section{References}

1) Keith, J.D., Rowe, R.D. \& Vlad, P. Heart Disease in Infancy and Childhood., 2nd ed., Macmillan, New York, 1967, p. 648.

2) Onoki, H., Sato, T., Kano, I. \& Mochizuki, K. Dye dilution curves after the artificial atrial septostomy in three infants with the transposition of the great vessels. Tohoku J. exp. Med., 1970, 100, 39-46.

3) Ochsner, J.L., Cooley, D.A., MacNamara, D.G. \& Kline, A. Surgical treatment of cardiovascular anomalies in 300 infants younger than one year of age. $J$. thorac. cardiov. Surg., 1962, 43, 182-198. 
4) Rashkind, W., Friedman, S., Waldhausen, J.A. \& Miller, W.W. Management of tricuspid atresia in infancy: Use of ballooncatheter arterial septostomy followed by ascending aorta to right pulmonary artery anastomosis. Circulation, 1967, 36 (suppl. II), II-217.

5) Rashkind, W.J. \& Miller, W.W. Creation of an atrial septal defect without thoracotomy: A palliative approach to complete transposition of the great arteries. J. Amer. med. Ass., 1966, 196, 991-992. 